\title{
Theoretical Study of Photochemical Hydrogen Abstraction by Triplet Aliphatic Carbonyls by Using Density Functional Theory
}

\author{
Caio L. Firme, ${ }^{* \dagger}{ }^{\dagger}$ Simon J. Garden, ${ }^{\ddagger}$ Nanci C. de Lucas, ${ }^{\ddagger}$ David E. Nicodem, ${ }^{\ddagger}$ and Rodrigo J. Correa* ${ }^{*}$ \\ ${ }^{\dagger}$ Universidade Federal do Rio Grande do Norte, Instituto de Química, Av. Salgado Filho, s/n, Lagoa Nova, Natal/RN, CEP \\ 59072-970, Brazil \\ ${ }^{\ddagger}$ Instituto de Química, Universidade Federal do Rio de Janeiro, Cidade Universitária, Ilha do Fundão, Centro de Tecnologia, Bloco A, \\ Rio de Janeiro, RJ, CEP 21949-900, Brazil
}

ABSTRACT: The density functional theory (DFT) and quantum theory of atoms in molecules (QTAIM) have been used to study the lowest lying spin states of the photochemical hydrogen abstraction reaction by formaldehyde, acetaldehyde, and acetone in the presence of different hydrogen donors: propane, 2-propanol, and methylamine. Calculations of all the critical points on the PES of these reactions were performed at $\mathrm{uB} 3 \mathrm{LYP} / 6-311++\mathrm{G}(\mathrm{d}, \mathrm{p})$. Methylamine is the best hydrogen donor, in thermodynamic and kinetic terms, followed by 2 propanol and finally propane. Secondary $\mathrm{C}-\mathrm{H}$ hydrogen abstraction in 2-propanol and $\mathrm{C}-\mathrm{H}$ abstraction in methylamine is thermodynamically and kinetically favored with respect to hydrogen abstraction from the $\mathrm{OH}$ and $\mathrm{NH}$ functional groups. Charge transfer takes place before the transition state when methylamine is the hydrogen donor, and for other hydrogen donors, charge transfer begins only in the transition state. The extent of the charge transfer in the transition states corresponds to about $50 \%$ of the total change in electron density of the oxygen atom of the $T_{1}$ carbonyl compounds during the course of the hydrogen abstraction reactions. The effect of solvent was investigated using the continuum solvation model for the reaction of triplet acetaldehyde in acetonitrile, which resulted in a barrierless transition state for hydrogen abstraction from methylamine.

\section{INTRODUCTION}

Hydrogen abstraction reactions occur in a diverse range of complex chemical or biological systems as exemplified by polymerizations, pyrolysis, and combustion processes as well as other chain reactions involving oxidative/reductive chemical/ biological reactions and are increasingly important in $\mathrm{C}-\mathrm{H}$ functionalization processes in synthetic organic/organometallic chemistry. ${ }^{1-13}$

With respect to the photochemical reactions of ketones, most of these can be divided into three categories: (1) $\alpha$-cleavage of the $\mathrm{C}-\mathrm{CO}$ bond; (2) hydrogen abstraction by the carbonyl oxygen atom; and (3) cycloaddition to an unsaturated carboncarbon bond. ${ }^{14-17}$

Low-lying triplet ketones from a $\pi, \pi^{*}$ electronic transition have low reactivity toward benzylic or aliphatic hydrogen abstraction, which occurs predominately from $n, \pi^{*}$ electronic transitions. ${ }^{18}$ Triplet aliphatic and aromatic carbonyls resemble alkoxyl radicals in hydrogen abstraction processes. ${ }^{19-21}$ Although theoretical and experimental studies ${ }^{22-27}$ show that singlet and triplet excited states of ketones are electronically similar in charge distribution, triplet acetone is much more reactive than its singlet excited state toward hydrogen abstraction. $^{28}$

Frequently, photochemical reactions of aliphatic ketones proceed exclusively from the triplet state because of its long lifetime. ${ }^{28,29}$ In the case of acetone, in the absence of external quenchers, its $S_{1}$ excited state is mainly deactivated through intersystem crossing to $\mathrm{T}_{1}\left(k_{\mathrm{ST}}=5 \times 10^{8} \mathrm{~s}^{-1}\right) .{ }^{30}$ This state is deactivated to $S_{0}$ with a considerably slower rate constant $\left(k_{\mathrm{D}} \approx\right.$ $\left.10^{6} \mathrm{~s}^{-1}\right)$. The rate constant for hydrogen abstraction from 2 propanol by triplet acetone has been experimentally determined $^{31,32}\left(k=10^{6} \mathrm{~mol}^{-1} \mathrm{~s}^{-1}\right)$ as well as from other hydrogen donors such as methanol, ${ }^{33}$ butanol, ${ }^{33}$ cyclohexane, ${ }^{33}$ diethylamine $^{33-35}$ and triethylamine. ${ }^{33-35}$ The mechanism of the hydrogen abstraction by triplet carbonyls depends upon the bond energy of the hydrogen donor and the reduction potential of the ketone. ${ }^{36-38}$ Hydrogen abstraction may occur by hydrogen atom transfer ${ }^{39}$ or by a proton coupled electron transfer-like mechanism. ${ }^{39-48}$

Computational methods have been used to evaluate both the nature of the excited state and its photochemistry. For the excited state, theoretical results of the geometrical parameters and the energetics correlate well with the experimental data. $^{49-58}$ The calculated structures, using the B3LYP functional, for $S_{1}$ formaldehyde and $S_{1}$ acetaldehyde, are very similar to the experimentally observed structures. ${ }^{57,59}$

Triplet aliphatic carbonyls have a pyramidalized structure. ${ }^{29,30,60}$ The nonplanar geometry of the ${ }^{1} \mathrm{~A}_{2}$ and ${ }^{3} \mathrm{~A}_{2}$ excited states of formaldehyde is due to vibronic pseudo Jahn-Teller mixing of these states with higher excited states of appropriate

Received: July 29, 2012

Revised: December 17, 2012

Published: December 18, 2012 

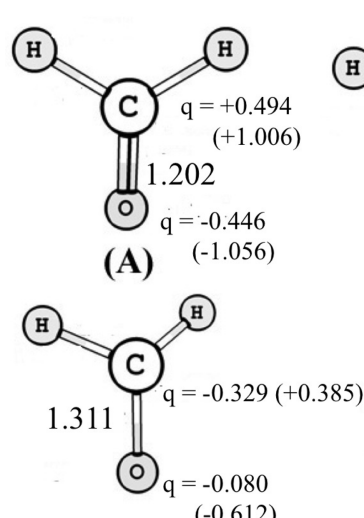

$\mathrm{H}-\mathrm{C}-\mathrm{H}-\mathrm{O}$

Out-of-plane bending angle $=42.2^{\circ}$

(D)
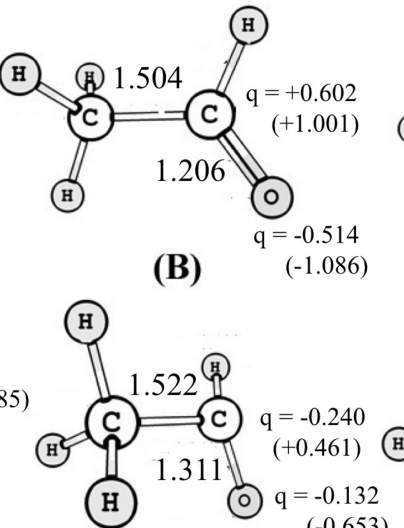

$\mathrm{H}-\mathrm{C}-\mathrm{CH}_{3}-\mathrm{O}$

Out-of-plane bending angle $=40.5^{\circ}$

(E)

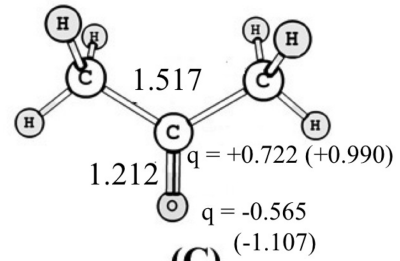

(C)

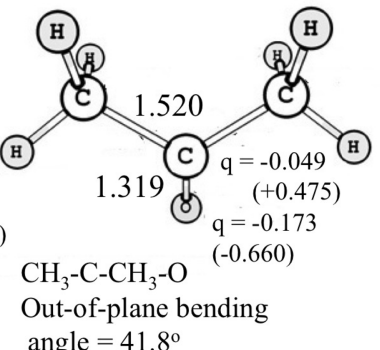

(F)

Figure 1. Bond lengths $[\mathrm{C}-\mathrm{C}$ and $\mathrm{C}-\mathrm{O}(\AA)]$ and atomic charges $[q=\mathrm{Chelpg}$ (and AIM), values are given in electrons $]$ for ground state $\left(\mathrm{S}_{0}\right) \mathbf{1}(\mathrm{A})$, $2(B)$, and $3(C)$, as well as the first triplet excited state $\left(T_{1}\right) \mathbf{l}(\mathrm{D}), 2(\mathrm{E})$, and $3(\mathrm{~F})$ and the out-of-plane bending angle (deg) for each of the $\mathrm{T}_{1}$ species.

symmetry. ${ }^{61}$ The energetics for hydrogen abstraction from methane by triplet formaldehyde ${ }^{62}$ and for the photoreduction of triplet acetone by methanol and dimethylamine were calculated by evaluating data for the bond dissociation energies of donors and reduced acceptors. ${ }^{63}$ Despite the computational data, information concerning the reaction mechanism for hydrogen abstraction by triplet aliphatic carbonyls is still lacking.

According to Gunnarsson and Lundqvist, ${ }^{64-66}$ the density functional techniques can be used to study the low-lying state of each spin or spatially irreducible representation because they represent the ground state of that particular symmetry. ${ }^{67}$ Therefore, it is possible to use density functional theory (DFT) to calculate only the lowest-lying triplet state of molecular systems. Our previous studies, in comparison with experimental results, validate this statement. ${ }^{68-70}$

In this study, we have used DFT to obtain geometrical, thermodynamic, and kinetic information on the hydrogen abstraction by aliphatic triplet carbonyls. A complementary study using quantum theory of atoms in molecules (QTAIM) was used to deepen the understanding of these photochemical reactions.

\section{COMPUTATIONAL METHODS}

The geometries of the studied species were optimized according to the Berny algorithm using energy-represented DIIS in redundant internal coordinates. ${ }^{71,72}$ Vibrational analysis on the optimized geometries of selected points of the potential energy surface (PES) was carried out in order to determine whether the resulting geometries are true minima or transition states, by checking for the existence of imaginary frequencies. All calculations were performed at the uB3LYP/6-311++G(d,p) level $^{73-75}$ by using the Gaussian 03 package. ${ }^{76}$ Initial geometries for the triplet complexes and triplet radical pairs were obtained from the corresponding calculated transition state (TS) structure by doing appropriate variations in some interatomic distances (for the atoms involved in the reaction) but keeping the same molecular conformation of the calculated transition state. The obtained geometries were subsequently corroborated by the use of internal reaction coordinate (IRC) calculations. For reactions with triplet acetaldehyde additional implicit solvation calculations based on IEFPCM model ${ }^{77,78}$ were done. Chelpg ${ }^{79}$ calculations in the gas phase were calculated at the same level of theory so as to study the charge distribution in the triplet carbonyls. The electronic density obtained at the uB3LYP/6-311++G(d,p) level was used for the QTAIM calculations. The molecular orbital energies for the triplet carbonyls and hydrogen donors were calculated using the ROHF/6-311++G(d,p) level of theory. ${ }^{80}$ The molecular graph and topological data ${ }^{81}$ were calculated by means of the AIM2000 software. ${ }^{82}$ The AIM atomic charges and population were calculated using the AIMALL package. ${ }^{83}$

\section{RESULTS}

We have used DFT to study the critical points of the PES for hydrogen abstraction by the triplets of formaldehyde (1), acetaldehyde (2), and acetone (3) from selected hydrogen donors (propane (4), 2-propanol (5), and methylamine (6)). We have previously applied this method to compare the theoretical results with experimental results for the phenolic hydrogen abstraction by the triplet state of cyclic $\alpha$ diketones. $^{68,70}$ Additionally, the DFT method has also been employed to investigate the photoreduction of 2-benzoylthiophene by phenol ${ }^{84,85}$ and the photoreduction of orthonaphthoquinones. ${ }^{86}$

3.1. Geometric Parameters. Initially, the structures of the three aliphatic carbonyl compounds $\mathbf{1}, \mathbf{2}$, and $\mathbf{3}$ were fully optimized in the ground state $\left(\mathrm{S}_{0}\right)$ and the first triplet excited state $\left(\mathrm{T}_{1}\right)$. The calculated $\mathrm{C}-\mathrm{C}$ (where appropriate) and $\mathrm{C}-\mathrm{O}$ bond lengths of the singlet $\left(S_{0}\right)$ and triplet $\left(T_{1}\right)$ states for the three aliphatic carbonyl compounds as well as atomic charges (Chelpg and AIM) and the out-of-plane bending angle (deg) for 1, 2, and 3 are presented in Figure 1.

In order to investigate the photochemical hydrogen abstraction from the hydrogen donors 4,5 , and 6 by the aliphatic triplet carbonyls, the mechanism was rationalized in three steps: (1) the formation of the triplet complex carbonyl/ hydrogen donor (TC); (2) a transition state for hydrogen abstraction (TS); and (3) the formation of a triplet radical pair (TRP) involving the ketyl radical, which has been exper- 

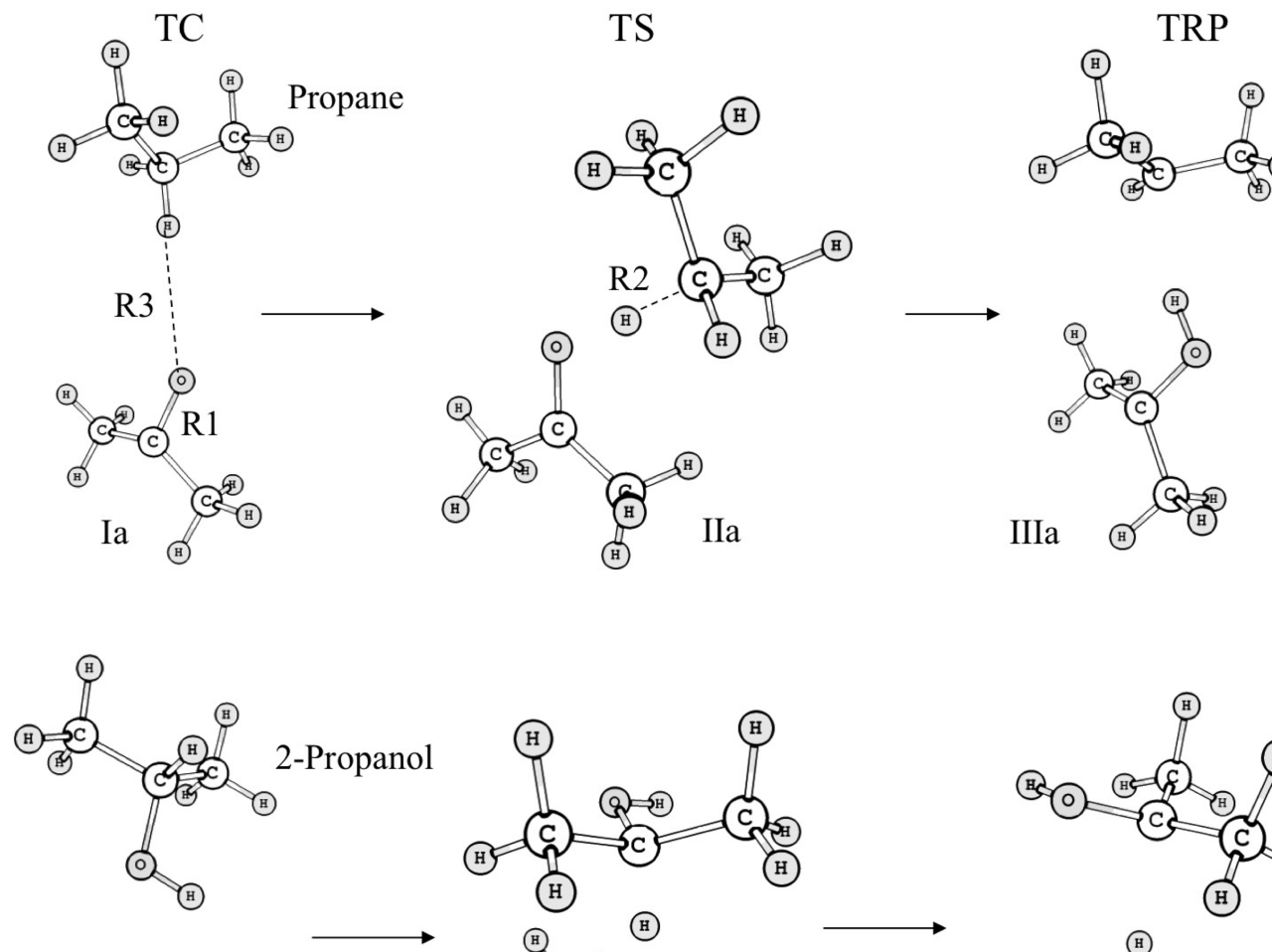

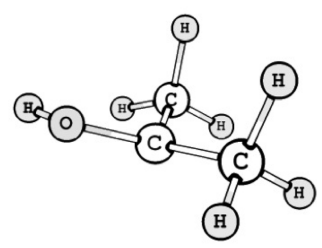

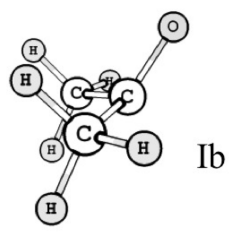<smiles>O=C(O)C1C(=O)OC(=O)C1C(=O)O</smiles><smiles>O=C(O)OC(=O)C(=O)O</smiles>

(H)
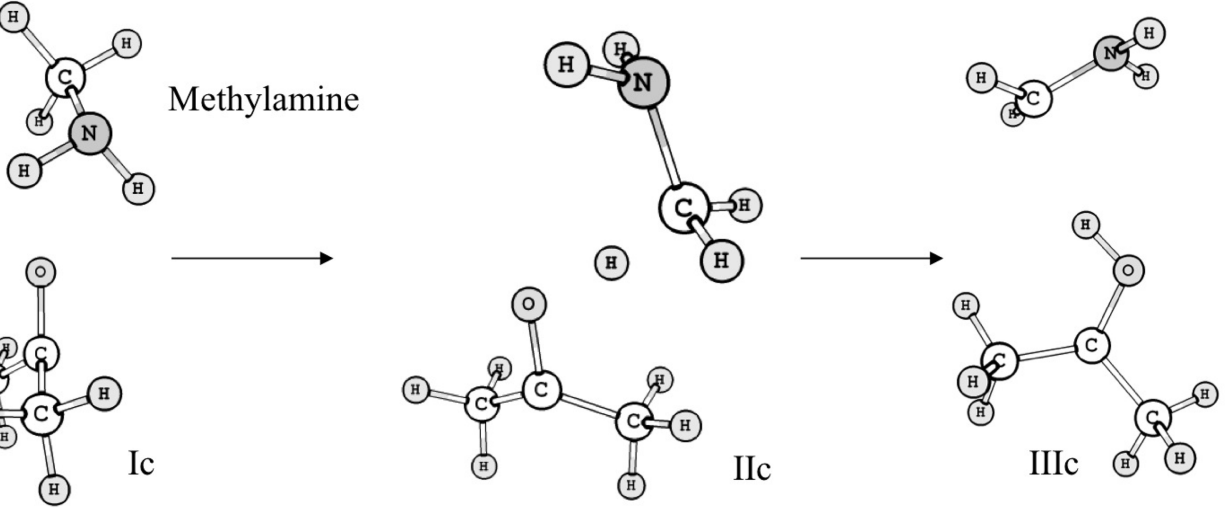

Figure 2. Triplet complex acetone/propane (Ia), TS acetone/propane (Ib), triplet radical pair acetone/propane (Ic); triplet complex acetone/2propanol (IIa), TS acetone/2-propanol (IIb) for $\mathrm{CH}$ bond cleavage, triplet radical pair acetone/2-propanol (IIc) resulting from $\mathrm{C}-\mathrm{H}$ bond cleavage; and triplet complex acetone/methylamine (IIIa), TS acetone/methylamine (IIIb) for $\mathrm{CH}$ bond cleavage, triplet radical pair acetone/methylamine (IIIc) resulting from $\mathrm{C}-\mathrm{H}$ bond cleavage.

imentally observed. ${ }^{87,88}$ Figure 2 exemplifies the optimized structures for the three steps of the reaction between triplet acetone (3) and the hydrogen donors $(4,5$, and 6$)$ by means of $\mathrm{CH}$ bond cleavage.

Table 1 details some calculated interatomic distances for $\mathrm{C} \cdots \mathrm{H}$ abstraction by the triplet carbonyl compounds with the studied hydrogen donors. The respective structures for $\mathrm{O}-\mathrm{H}$ or $\mathrm{N}-\mathrm{H}$ abstractions were calculated, but geometric parameters for the $\mathrm{X}-\mathrm{H}(\mathrm{X}=\mathrm{N}$ or $\mathrm{O})$ cleavage are not given in Table 1 as the $\mathrm{X}-\mathrm{H}$ abstraction is less likely to occur as determined from the changes in energy during the reaction in comparison with the corresponding $\mathrm{C}-\mathrm{H}$ abstractions (see Table 2).

A complementary study using the QTAIM was performed in order to investigate the topological relationship between the carbonyl compounds and the hydrogen donors for all the studied critical points of the PES. From the gradient of a molecular electronic density or charge density, the QTAIM algorithm finds different types of critical points (where the gradient is zero). The most important of these is the bond critical point $(\mathrm{BCP})$ that interconnects bonded atoms through 
Table 1. Calculated Interatomic Distances $(\AA)$ between Carbon and Oxygen Atoms of the $\mathrm{T}_{1}$ Carbonyl Group (R1), Carbon and Hydrogen Atoms (Where $\mathrm{H}$ Is the Abstracted Atom) of the Hydrogen Donors (R2), and Interatomic Distances between Oxygen (Carbonyl Group) and Hydrogen (Hydrogen Donor) Atoms (R3) for the Studied Critical Points of the PES

\begin{tabular}{|c|c|c|c|c|c|}
\hline \multirow[b]{2}{*}{$\begin{array}{l}\text { carbonyl } \\
\text { compound }\end{array}$} & \multirow[b]{2}{*}{$\begin{array}{c}\text { hydrogen } \\
\text { donor }\end{array}$} & \multirow[b]{2}{*}{$\begin{array}{c}\text { mechanistic } \\
\text { step }^{a}\end{array}$} & \multicolumn{3}{|c|}{ interatomic distances $(\AA)$} \\
\hline & & & $\begin{array}{c}\mathrm{R} 1 \\
(\mathrm{CO})\end{array}$ & $\underset{(\mathrm{CH})^{b}}{\mathrm{R} 2}$ & $\begin{array}{c}\mathrm{R} 3 \\
(\mathrm{CO} \cdots \mathrm{H})\end{array}$ \\
\hline \multirow[t]{9}{*}{1} & \multirow[t]{3}{*}{4} & $\mathrm{TC}$ & 1.303 & 1.096 & 2.829 \\
\hline & & TS & 1.341 & 1.246 & 1.305 \\
\hline & & TRP & 1.362 & 2.165 & 0.974 \\
\hline & \multirow[t]{3}{*}{5} & $\mathrm{TC}$ & 1.299 & 1.092 & 4.724 \\
\hline & & TS & 1.335 & 1.207 & 1.394 \\
\hline & & TRP & 1.363 & 2.100 & 0.977 \\
\hline & \multirow[t]{3}{*}{6} & $\mathrm{TC}$ & 1.308 & 1.121 & 1.830 \\
\hline & & TS & 1.327 & 1.204 & 1.420 \\
\hline & & TRP & 1.360 & 2.062 & 0.982 \\
\hline \multirow[t]{9}{*}{2} & \multirow[t]{3}{*}{4} & $\mathrm{TC}$ & 1.311 & 1.096 & 2.822 \\
\hline & & TS & 1.349 & 1.239 & 1.315 \\
\hline & & TRP & 1.372 & 2.197 & 0.972 \\
\hline & \multirow[t]{3}{*}{5} & $\mathrm{TC}$ & 1.308 & 1.099 & 4.740 \\
\hline & & TS & 1.342 & 1.198 & 1.413 \\
\hline & & TRP & 1.372 & 2.125 & 0.976 \\
\hline & \multirow[t]{3}{*}{6} & $\mathrm{TC}$ & 1.290 & 1.116 & 1.819 \\
\hline & & TS & 1.333 & 1.191 & 1.451 \\
\hline & & TRP & 1.369 & 2.089 & 0.980 \\
\hline \multirow[t]{9}{*}{3} & \multirow[t]{3}{*}{4} & $\mathrm{TC}$ & 1.319 & 1.095 & 2.937 \\
\hline & & TS & 1.356 & 1.249 & 1.308 \\
\hline & & TRP & 1.380 & 2.285 & 0.971 \\
\hline & \multirow[t]{3}{*}{5} & $\mathrm{TC}$ & 1.322 & 1.101 & 4.106 \\
\hline & & TS & 1.351 & 1.211 & 1.403 \\
\hline & & TRP & 1.380 & 2.197 & 0.974 \\
\hline & \multirow[t]{3}{*}{6} & $\mathrm{TC}$ & 1.328 & 1.103 & 2.460 \\
\hline & & TS & 1.345 & 1.190 & 1.456 \\
\hline & & TRP & 1.378 & 2.150 & 0.977 \\
\hline
\end{tabular}

${ }^{a_{\mathrm{TC}}}=$ triplet complex; $\mathrm{TS}=$ transition state; TRP $=$ triplet radical pair. ${ }^{b} \mathrm{C}-\mathrm{H}$ bond lengths of the hydrogen donors (R2), before forming the triplet complex with the triplet carbonyl compounds, are $1.096 \AA$ (4), $1.100 \AA$ (5), and $1.093 \AA$ (6).

a bond path that, in turn, represents the path with the largest value of charge density between the bonded atomic basins (or atoms). Every true bond path is mirrored by their corresponding virial path. The virial paths have the largest negative potential energy density between two atoms. The conjunction of critical points of the charge density and bond paths is called the molecular graph. Therefore, QTAIM can be used to infer the existence, or not, of an (inter)molecular interaction because the bond path is indicative of a bonded interaction in an atomic pair, which is mirrored by their corresponding virial path. ${ }^{89}$

Figure 3 illustrates the molecular graphs of the triplet 1-4, triplet 1-5, and triplet 1-6 transition states and the corresponding BCPs 1,2 , and 3 . The bond paths relative to the BCPs 1,2 , and 3 are mirrored by their corresponding virial paths. Table 2 details the charge density for the respective BCPs of the TC, TS, and TRP for the carbonyl triplets 1-3 reacting with the hydrogen donors 4-6.
Table 2. Charge Density in Bond Critical Points $\left(\rho_{\mathrm{b}}\right) 1,2$, and 3 (in au) for the Triplet Complexes, Transition States, and Triplet Radical Pairs ${ }^{a}$

\begin{tabular}{|c|c|c|c|c|c|}
\hline \multirow[b]{2}{*}{$\begin{array}{c}\text { carbonyl } \\
\text { compound }\end{array}$} & \multirow[b]{2}{*}{$\begin{array}{l}\text { hydrogen } \\
\text { donor }\end{array}$} & \multirow[b]{2}{*}{$\begin{array}{l}\text { mechanistic } \\
\text { step }\end{array}$} & \multicolumn{3}{|c|}{$\rho_{\mathrm{b}}(\mathrm{au})$} \\
\hline & & & 1 & 2 & 3 \\
\hline \multirow[t]{9}{*}{1} & 4 & TC & & 0.274 & 0.004 \\
\hline & & TS & & 0.181 & 0.137 \\
\hline & & TRP & & 0.019 & 0.353 \\
\hline & 5 & TC & 0.017 & & \\
\hline & & TS & 0.007 & 0.209 & 0.109 \\
\hline & & TRP & & 0.024 & 0.349 \\
\hline & 6 & TC & 0.010 & 0.258 & 0.035 \\
\hline & & TS & 0.008 & 0.206 & 0.102 \\
\hline & & TRP & & 0.026 & 0.344 \\
\hline \multirow[t]{9}{*}{2} & 4 & TC & & 0.275 & 0.004 \\
\hline & & TS & & 0.184 & 0.133 \\
\hline & & TRP & & 0.018 & 0.354 \\
\hline & 5 & TC & 0.016 & & \\
\hline & & TS & 0.007 & 0.214 & 0.103 \\
\hline & & TRP & & 0.022 & 0.350 \\
\hline & 6 & $\mathrm{TC}$ & & 0.262 & 0.031 \\
\hline & & TS & 0.008 & 0.213 & 0.094 \\
\hline & & TRP & & 0.024 & 0.346 \\
\hline \multirow[t]{9}{*}{3} & 4 & TC & & 0.275 & 0.003 \\
\hline & & TS & & 0.164 & 0.123 \\
\hline & & TRP & & 0.015 & 0.356 \\
\hline & 5 & TC & 0.018 & & \\
\hline & & TS & 0.006 & 0.206 & 0.106 \\
\hline & & TRP & 0.004 & 0.019 & 0.352 \\
\hline & 6 & TC & 0.019 & & \\
\hline & & TS & & 0.214 & 0.092 \\
\hline & & TRP & & 0.021 & 0.349 \\
\hline
\end{tabular}

${ }^{a}$ An empty cell indicates that no BCP was found at the corresponding point.

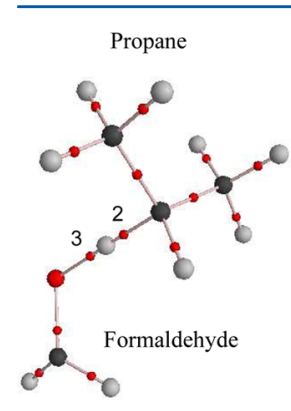

(A)

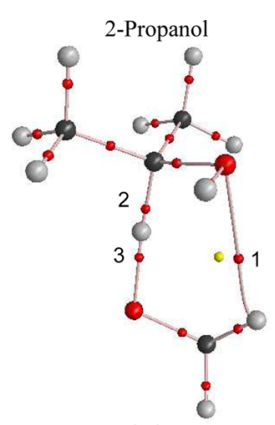

(B)

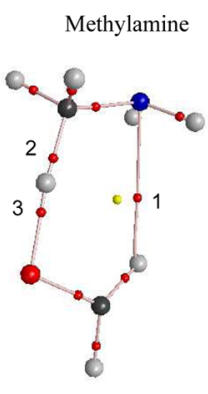

(C)
Figure 3. Molecular graphs of the transition states for the hydrogen abstraction reactions between triplets 1 and 4 (A), triplets 1 and 5 (B), and triplets 1 and $6(\mathrm{C})$.

As the reaction passes from the TS to the TRP, the magnitudes of BCPs 2 and 3 invert, indicating the formation of a new $\mathrm{H}-\mathrm{O}$ bond and the cleavage of the $\mathrm{C}-\mathrm{H}$ bond.

Figure 4 shows the molecular graph for the TCs 1-5, 2-5, and 3-5 that lead to $\mathrm{CH}$ cleavage (I) or to $\mathrm{OH}$ cleavage (II).

With respect to the TCs $\mathbf{1 - 5}$ and 2-5 (Figure 4, IA and IB) both reveal an $\mathrm{R}(\mathrm{O}) \mathrm{C}-\mathrm{H} \cdots \mathrm{O}(\mathrm{H}) \mathrm{R}^{\prime}$ hydrogen bond between the aldehyde $\alpha-\mathrm{H}$ and the oxygen atom of 5 , while the triplet complex 3-5 (Figure 4, IC) has a (3) C-O $\cdots \mathrm{H}-\mathrm{O}$ (5) hydrogen bond. These atomic arrangements apparently do not 
Triplet complex of carbonyl compound and 2-propanol preceding $\mathrm{CH}$ bond cleavage

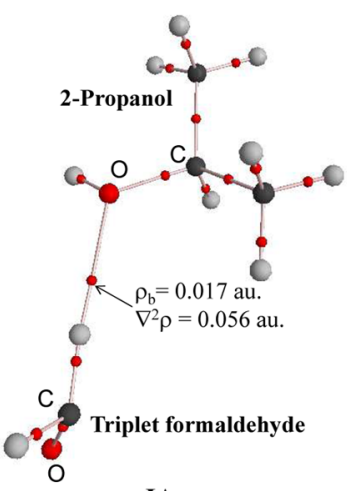

IA

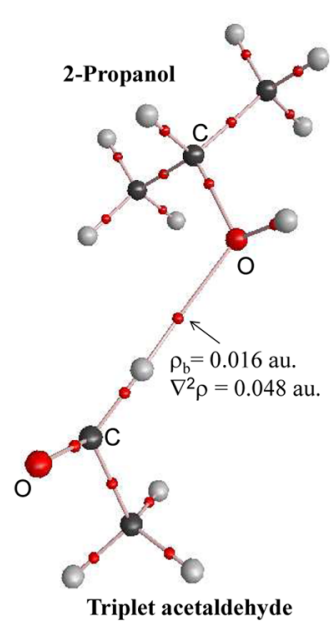

IB

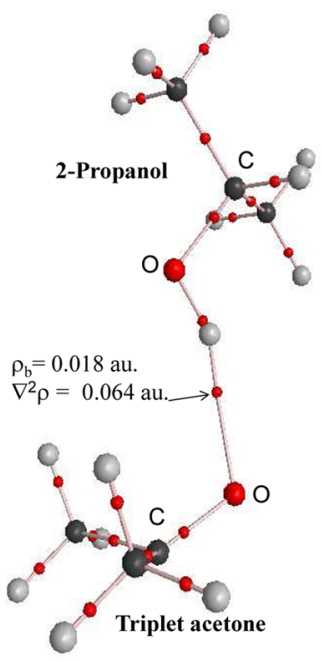

IC

Triplet complex of carbonyl compound and 2-propanol preceding $\mathrm{OH}$ bond cleavage

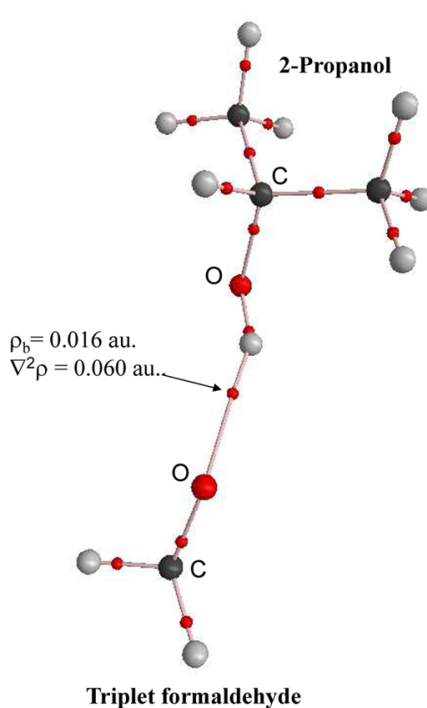

IIA

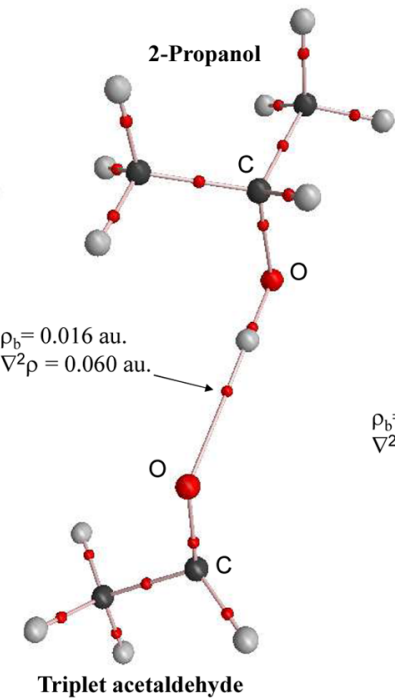

IIB

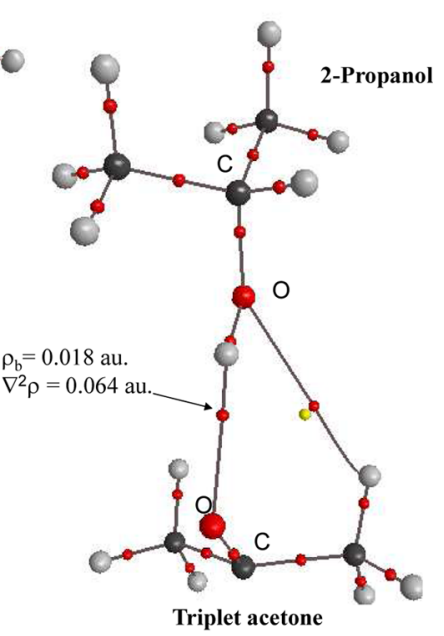

IIC

Figure 4. Molecular graphs of the TCs between the carbonyl compounds (1, 2, and $\mathbf{3})$ and $\mathbf{5}$ that lead to $\mathrm{CH}$ cleavage (IA, IB, and IC, respectively) and the molecular graphs of the triplet complex between the carbonyl compounds $(\mathbf{1}, \mathbf{2}$, and $\mathbf{3})$ and $\mathbf{5}$ that lead to OH cleavage (IIA, IIB, and IIC, respectively) as well as the charge density, $\rho_{\mathrm{b}}$, and the Laplacian of the charge density, $\nabla^{2} \rho_{\mathrm{b}}$, for relevant BCPs.

Scheme 1. Hydrogen Abstraction from the $\mathrm{H}-\mathrm{O}$ Bond of 5 by Triplets 1, 2, or 3

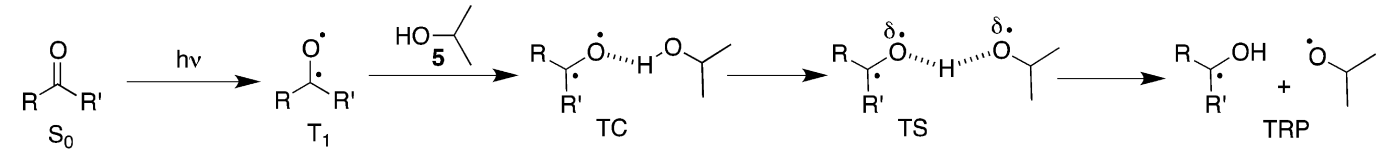$$
1 R=R^{\prime}=H
$$$$
2 \mathrm{R}=\mathrm{H}, \mathrm{R}^{\prime}=\mathrm{Me}
$$$$
3 R=R^{\prime}=M e
$$

readily present a conformation that would allow $\mathrm{C}-\mathrm{H}$ abstraction from $\mathbf{5}$. However, the unexpected energy minimized structures of the TCs were confirmed by IRC calculations starting from the TS structures. Additionally, attempts to localize TCs with a (carbonyl) $\mathrm{CO} \cdots \mathrm{H}-\mathrm{C}$ (hydrogen donor) interaction, an interaction that would afford a molecular conformation closer to that found in the corresponding TS structures, were all unsuccessful and yielded the depicted TCs.
Therefore, the polar interactions observed, $(\mathrm{O}) \mathrm{C}-\mathrm{H} \cdots \mathrm{O}(\mathrm{H})$ or $\mathrm{C}-\mathrm{O} \cdots \mathrm{H}-\mathrm{O}$, in the TCs give rise to more stable intermediate structures with smaller total energies.

With respect to the TCs for hydrogen abstraction by $\mathrm{OH}$ cleavage, all TCs reveal a (carbonyl) $\mathrm{CO} \cdots \mathrm{H}-\mathrm{O}$ hydrogen bond structure (Figure 4, IIA, IIB, and IIC).

Some topological data of the bond critical points (charge density of the critical point, $\rho_{\mathrm{b}}$, and Laplacian of the charge 
density of the critical point, $\left.\nabla \rho_{\mathrm{b}}\right)$ for the interactions $(\mathrm{O}) \mathrm{C}-$ $\mathrm{H} \cdots \mathrm{O}(\mathrm{H})$ and $\mathrm{C}-\mathrm{O} \cdots \mathrm{H}-\mathrm{O}$ (in $\mathrm{IA}, \mathrm{IB}$, and $\mathrm{IC}$ ) and for the $\mathrm{CO} \cdots \mathrm{H}-\mathrm{O}$ hydrogen bond (in IIA, IIB, and IIC) are also shown in Figure 4.

3.2. Energetics of the Potential Energy Surface. In the case of hydrogen abstraction from 5 or $\mathbf{6}$, hydrogen abstraction could involve either $\mathrm{X}-\mathrm{H}(\mathrm{O}-\mathrm{H}$ from 5 or $\mathrm{N}-\mathrm{H}$ from 6$)$ or $\mathrm{C}-\mathrm{H}$ bond cleavage. Scheme 1 depicts the $\mathrm{O}-\mathrm{H}$ abstraction reaction between triplet carbonyl compounds $(1,2$, and 3$)$ and 5.

Triplet energies were theoretically evaluated for the aliphatic ketones, and the calculated triplet energies of the three carbonyl compounds are reasonably similar to the experimental values (formaldehyde, ${ }^{49} 80.5 \mathrm{kcal} \cdot \mathrm{mol}^{-1}$, calculated $83.5 \mathrm{kcal} \cdot \mathrm{mol}^{-1}$; acetaldehyde, ${ }^{90} 75.7 \mathrm{kcal} \cdot \mathrm{mol}^{-1}$, calculated $70.9 \mathrm{kcal} \cdot \mathrm{mol}^{-1}$; acetone, $^{91} 79 \mathrm{kcal} \cdot \mathrm{mol}^{-1}$, calculated $\left.74.6 \mathrm{kcal} \cdot \mathrm{mol}^{-1}\right)$. The calculated values for the triplet energies of formaldehyde, acetaldehyde, and acetone in this study agree well with calculated values from other studies. ${ }^{55,92}$

The calculated activation free-energies and the change in free energy for the hydrogen abstraction reactions are presented in Table 3. The analysis of the hydrogen abstraction reactions

Table 3. Values of the Calculated Activation Free Energy $\left(\Delta G_{\mathrm{TS}}\right)$ and the Change in Reaction Free Energy $\left(\Delta G_{\text {reac }}\right)$ for the Reaction of the Triplet Carbonyls (1, 2, and 3) with the Hydrogen Donors (4, 5, and 6)

$\begin{array}{lll}\text { reaction } & \Delta G_{\mathrm{TS}}\left(\mathrm{kcal} \cdot \mathrm{mol}^{-1}\right) & \Delta G_{\text {reac }}\left(\mathrm{kcal} \cdot \mathrm{mol}^{-1}\right) \\ \mathbf{1}^{a}+\mathbf{4}^{b} & 8.28 & -3.74 \\ \mathbf{1}+\mathbf{5}(\mathrm{OH})^{c} & 9.53 & 0.44 \\ \mathbf{1}+\mathbf{5}(\mathrm{CH})^{d} & 4.86 & -8.25 \\ \mathbf{1}+\mathbf{6}(\mathrm{NH}) & 2.76 & -7.07 \\ \mathbf{1}+\mathbf{6}(\mathrm{CH}) & 0.10 & -12.50 \\ \mathbf{2}^{e}+\mathbf{4} & 8.22(10.74)^{h} & -4.96(-2.55)^{h} \\ \mathbf{2}+\mathbf{5}(\mathrm{OH}) & 8.87 & -0.45 \\ \mathbf{2}+\mathbf{5}(\mathrm{CH}) & 4.86(4.97)^{h} & -10.23(-10.32)^{h} \\ \mathbf{2}+\mathbf{6}(\mathrm{NH}) & 2.46 & -8.29 \\ \mathbf{2}+\mathbf{6}^{f}(\mathrm{CH}) & 1.16(-) & -12.76(-) \\ \mathbf{3}^{g}+\mathbf{4} & 10.22 & -4.59 \\ \mathbf{3}+\mathbf{5}(\mathrm{OH}) & 8.67 & -0.88 \\ \mathbf{3}+\mathbf{5}(\mathrm{CH}) & 4.95 & -10.24 \\ \mathbf{3}+\mathbf{6}(\mathrm{NH}) & 5.10 & -8.14 \\ \mathbf{3}+\mathbf{6}(\mathrm{CH}) & 0.49 & -13.85\end{array}$

${ }^{a}$ The calculated formaldehyde triplet energy is $83.46 \mathrm{kcal} \cdot \mathrm{mol}^{-1} \cdot{ }^{b} \mathrm{C}-$ $\mathrm{H}$ bond cleavage in $\mathrm{C} 2 .{ }^{c} \mathrm{O}-\mathrm{H}$ bond cleavage. ${ }^{d} \mathrm{C}-\mathrm{H}$ bond cleavage. ${ }^{e}$ The calculated acetaldehyde triplet energy is $70.93 \mathrm{kcal} \cdot \mathrm{mol}^{-1} .{ }^{f_{\text {No }}}$ TC or TS were found for reaction between $\mathrm{T}_{1}-\mathbf{2}$ and $\mathbf{6}$ in acetonitrile. ${ }^{g}$ The calculated acetone triplet energy is $74.56 \mathrm{kcal} \cdot \mathrm{mol}^{-1}$. ${ }^{h}$ Activation free energy and change in reaction free energy for the reactions of triplet acetaldehyde with hydrogen donors from IEFPCM calculations with acetonitrile as solvent.

from the $\mathrm{OH}$ or $\mathrm{NH}$ groups in 2-propanol or methylamine by the triplets 1,2 or 3 reveals that these reactions have larger activation energies and that they are less exergonic than the corresponding reactions involving the respective $\alpha-\mathrm{CH}$ bond abstraction (Table 3). Additionally, Table 3 allows comparison of the results, activation energy $\left(\Delta G_{\mathrm{TS}}\right)$, and $\Delta G_{\text {reac }}$ for the reaction of triplet 2 with the hydrogen donors 4 and 5 in the presence of solvent (acetonitrile, by use of the continuum solvation model). Unfortunately the respective TC and TS for the reaction of triplet $\mathbf{2}$ with $\mathbf{6}$ could not be localized. Similarly, no TS was found for other reactions with methylamine for $\mathrm{CH}$ bond cleavage when using IEFPCM calculations with acetonitrile as solvent.

Figure 5 shows the energies for the critical points (TC, TS, and TRP) on the PES, relative to the corresponding complex in the $\mathrm{S}_{0}$ state, for the hydrogen abstraction reactions $(\mathrm{C}-\mathrm{H}, \mathrm{O}-$ $\mathrm{H}$, or $\mathrm{N}-\mathrm{H})$ by the triplet carbonyl compounds $(1,2$, and 3 ) from 5 and 6 .

3.3. Charge Analysis of the Critical Points. A comparison of the atomic charges (from Chelpg and AIM calculations) of the singlet $\left(\mathrm{S}_{0}\right)$ and triplet $\left(\mathrm{T}_{1}\right)$ states for the three aliphatic carbonyl compounds $\mathbf{1}, \mathbf{2}$, and 3 is presented in Figure 1 . The negative charge of the oxygen atom increases for each state in the order $\mathbf{1}<\mathbf{2}<3$ as a consequence of the inductive effect of an increasing number of electron donating methyl groups. The oxygen atom of the $S_{0}$ state is more negatively charged than the $T_{1}$ state, thus revealing the electrophilic nature of the oxygen atom of the $T_{1}$ state in comparison to the ground $S_{0}$ state. However, the partial charge of the carbonyl carbon atoms becomes more negative (Chelpg) or less positive (AIM charges) on passing from $S_{0}$ to $T_{1}$ as expected from an increase of the electron density on the carbon atoms due to unpairing of the electron spins. In the case of $T_{1}$, the order of decreasing negative charge on the carbonyl carbon atom is $\mathbf{1}>\mathbf{2}>3$. The consequence of the charge distribution in triplets 1,2 , and 3 is that the oxygen atom of $T_{1}$ formaldehyde is the most electrophilic, while the oxygen atom of $\mathrm{T}_{1}$ acetone is the least electrophilic.

Table 4 presents the Chelpg and AIM atomic charges and AIM atomic charges of carbon and oxygen of the carbonyl group and chelpg total electron population of 1,2 , and 3 at each critical point of the PES (TC, TS, and TRP).

The atomic charge of the carbon and oxygen atoms of the carbonyl group changes on passing from the isolated triplet carbonyl compounds (Figure 1) to the corresponding triplet complexes. For the triplet complexes involving propane, the atomic charge (Chelpg) of the carbonyl oxygen atom becomes less negative when compared to that from the corresponding isolated triplet carbonyl compound. For the triplet complexes involving 2-propanol and methylamine, the atomic charge (both Chelpg and AIM) of the carbonyl oxygen atom becomes more negative in comparison to the corresponding isolated triplet carbonyl compound, except for acetone/methylamine triplet complex. The opposite occurs with the atomic charge of the carbonyl carbon atom: more negative atomic charge for reactions with propane and less negative atomic charge for reactions with 2-propanol and methylamine (according to Chelpg atomic charges), except for the acetone/2-propanol and acetone/methylamine triplet complexes.

3.4. Analysis of the Electrophilicity and Nucleophilicity Indexes. The electrophicility index of each carbonyl triplet was analyzed (Table 5) by using the energy gap of the frontier orbitals (SOMO-LUMO) to evaluate the global electrophicility index, ${ }^{93,94} w$, in a manner analogous to ground state singlets where $w=\left[\left(\varepsilon_{\mathrm{H}}+\varepsilon_{\mathrm{L}}\right) / 2\right]^{2} / 2\left(\varepsilon_{\mathrm{L}}-\varepsilon_{\mathrm{H}}\right)$. The corresponding nucleophicility index, $N$, of the hydrogen donors was determined from the difference in the HOMO energies of the nucleophile and the reference compound (tetracyanoethylene). ${ }^{95}$ In our case, for triplet carbonyls, SOMO replaces $\mathrm{HOMO}$, and $\mathrm{MO}$ energies were calculated using a restricted open-shell Hartree-Fock calculation. ${ }^{80}$ The results for the triplet carbonyl compounds (Table 5) are consistent with the atomic charge data presented in Figure 1, indicating that triplet 
Hydrogen abstraction reaction by 1,2 and 3 from 2-propanol

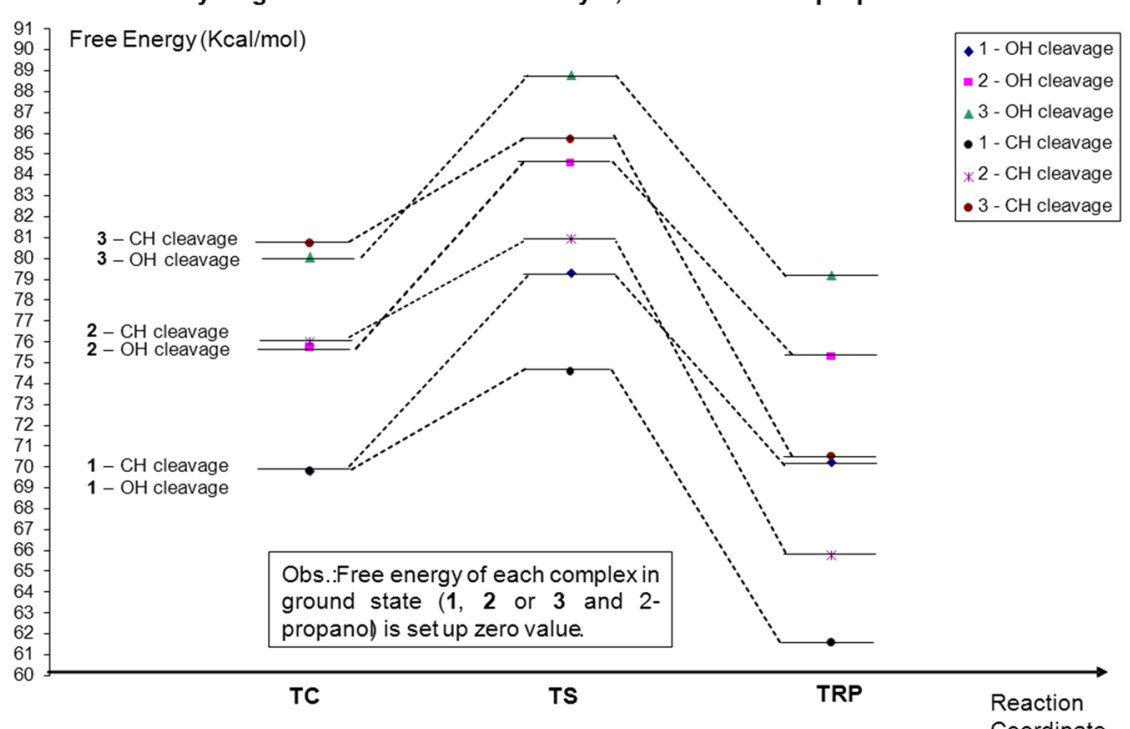

Hydrogen abstraction reaction by 1,2 and 3 from methylamine Coordinate

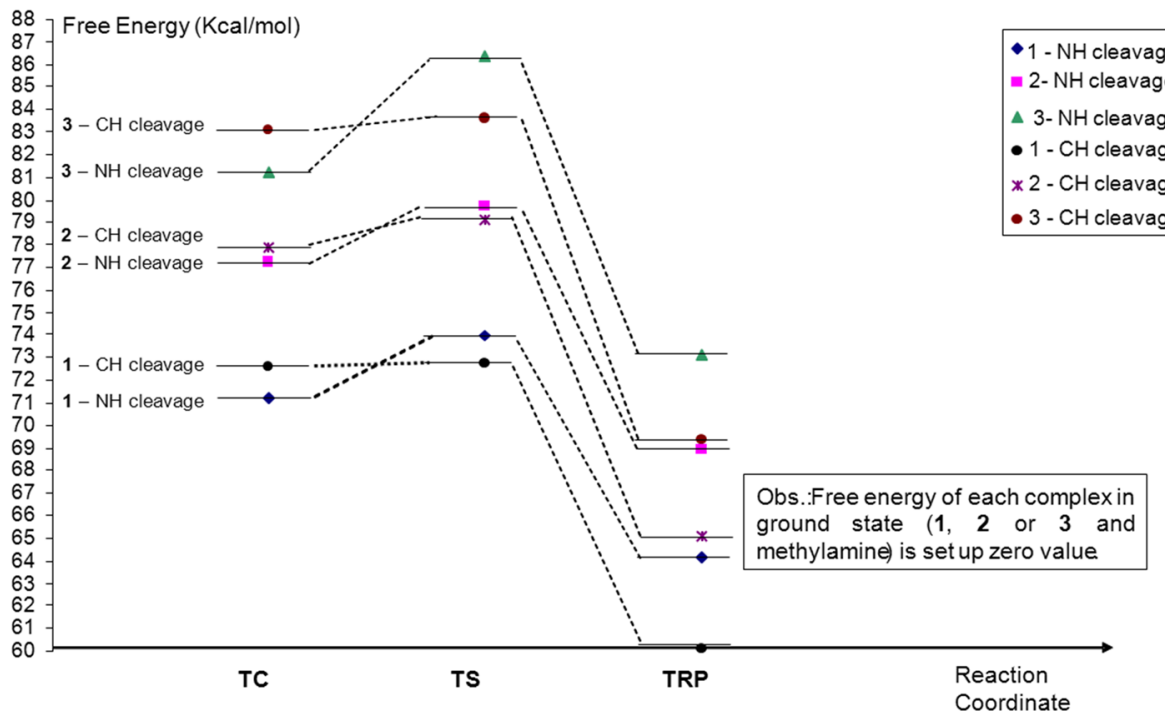

Figure 5. Reaction coordinate for the hydrogen abstraction reactions by triplet carbonyl compounds (1, 2, and 3$)$ from 5 and $6(\mathrm{C}-\mathrm{H}$ and $\mathrm{O}-\mathrm{H}$ or $\mathrm{N}-\mathrm{H}$ cleavage).

formaldehyde and triplet acetone, respectively, have the most and least electrophilic character.

\section{DISCUSSION}

The mechanism for hydrogen abstraction by $T_{1}$ carbonyl compounds was rationalized in three steps: (1) formation of the carbonyl/hydrogen donor TC; (2) a hydrogen abstraction TS; and (3) formation of the TRP. With respect to the triplet carbonyl compounds, the geometric parameters, calculated using the DFT methodology, for the $S_{0}$ and $T_{1}$ states (Figure 1) are very similar to values reported in the literature. The $\mathrm{C}-\mathrm{O}$ bond lengths of $S_{0}$ and $T_{1}$ formaldehyde are 1.209 and $1.316 \AA$, respectively, by using the $\operatorname{CCSD}(\mathrm{T}) / \operatorname{ccpV}(\mathrm{T}+\mathrm{d}) \mathrm{Z}$ method. ${ }^{96}$ The $\mathrm{C}-\mathrm{O}$ bond length of $\mathrm{T}_{1}$ acetaldehyde is $1.323 \AA$ by using the UMP2(full)/6-311G(d,p) method. ${ }^{97}$ The $\mathrm{C}-\mathrm{O}$ bond length of $\mathrm{T}_{1}$ acetone is $1.370 \AA$ by using the $\operatorname{CASSCF}(8,7)$ / $6-31 \mathrm{G}(\mathrm{d})$ method. $^{98}$ In all cases, the $\mathrm{C}-\mathrm{O}$ bond is approximately $10 \%$ longer in the $T_{1}$ state relative to the $S_{0}$ state. The pyramidalized structures of the $T_{1}$ states of 1,2 , and 3 are depicted by the out-of-plane bending angles of about $41 \pm$ $1^{\circ}$. These values are similar to those reported in the preceding literature.

The $\mathrm{C}-\mathrm{H}$ bond lengths (R2) of the hydrogen donors before forming the TC are $1.096 \AA$ (4), $1.100 \AA$ (5), and $1.093 \AA$ (6). Formation of a TC involving 1, 2, or 3 with either 4 or 5 has little effect upon R2 as the geometry optimized TCs reveal no interaction between the carbonyl oxygen and the hydrogen atom to be abstracted. However, formation of the TC between 6 and the triplet carbonyls 1,2 , or 3 , results in an increase in $\mathrm{R} 2$. The increase in $\mathrm{R} 2$ is greatest for $\mathbf{1}$ and least for 3. This reveals that the increase in $\mathrm{R} 2$ is dependent upon the electrophilicity of the carbonyl triplet. The difference in the electrophilicities of $\mathbf{1}, \mathbf{2}$, and 3 can be seen in Table 5, where an order of magnitude difference in the electrophilicity index between $\mathrm{T}_{1} \mathbf{1}$ and 3 was calculated based upon the energies of the frontier orbitals.

The $\mathrm{C}-\mathrm{O}$ triplet bond length increases by 2 to $3 \%$ on passing from the TC to the TS, while the increase in the $\mathrm{C}-\mathrm{H}$ bond length of the hydrogen donors is dependent upon the nature of the hydrogen donor ( $15 \%$ for $4,11 \%$ for 5 , and $7 \%$ 
Table 4. Chelpg and AIM Atomic Charges of the Carbon and Oxygen Atoms of the Carbonyl Group and Chelpg Electron Population of 1, 2, and 3 at Each Critical Point of the PES for the Gas Phase CH Abstraction Reactions with the Hydrogen Donors 4, 5, and 6 (in au)

\begin{tabular}{|c|c|c|c|c|c|c|}
\hline \multirow[b]{2}{*}{$\begin{array}{l}\text { carbonyl } \\
\text { compound }\end{array}$} & \multirow[b]{2}{*}{$\begin{array}{l}\text { hydrogen } \\
\text { donor }\end{array}$} & \multirow[b]{2}{*}{$\begin{array}{l}\text { mechanistic } \\
\text { step }\end{array}$} & \multicolumn{3}{|c|}{ Chelpg (and AIM) atomic charge of the carbonyl group } & \multirow[b]{2}{*}{$\begin{array}{c}\text { Chelpg (and AIM) electron population of 1, 2, } \\
\text { and } 3\end{array}$} \\
\hline & & & $\mathrm{C} 1$ & O1 & $\mathrm{C} 1+\mathrm{O} 1$ & \\
\hline \multirow[t]{9}{*}{$1^{a, b}(16)^{c}$} & 4 & TC & $-0.36(0.45)$ & $-0.04(-0.64)$ & $-0.40(-0.19)$ & $15.98(16.00)$ \\
\hline & & TS & $-0.33(0.42)$ & $-0.25(-0.83)$ & $-0.58(-0.41)$ & $16.27(16.33)$ \\
\hline & & TRP & $-0.27(0.42)$ & $-0.40(-1.08)$ & $-0.67(-0.66)$ & $17.09(17.04)$ \\
\hline & 5 & $\mathrm{TC}$ & $-0.30(0.41)$ & $-0.13(-0.67)$ & $-0.43(-0.26)$ & $15.99(16.01)$ \\
\hline & & TS & $-0.31(0.41)$ & $-0.24(-0.83)$ & $-0.55(-0.42)$ & $16.24(16.31)$ \\
\hline & & TRP & $-0.23(0.41)$ & $-0.36(-1.08)$ & $-0.59(-0.67)$ & $17.17(17.05)$ \\
\hline & 6 & $\mathrm{TC}$ & $-0.32(0.44)$ & $-0.15(-0.76)$ & $-0.47(-0.32)$ & $16.18(16.21)$ \\
\hline & & TS & $-0.29(0.43)$ & $-0.27(-0.85)$ & $-0.56(-0.42)$ & $16.30(16.37)$ \\
\hline & & TRP & $-0.27(0.42)$ & $-0.38(-1.09)$ & $-0.65(-0.67)$ & $17.14(17.07)$ \\
\hline \multirow[t]{9}{*}{$2^{a, b}(24)^{c}$} & 4 & $\mathrm{TC}$ & $-0.27(0.46)$ & $-0.09(-0.66)$ & $-0.36(-0.20)$ & $23.98(24.00)$ \\
\hline & & $\mathrm{TS}$ & $-0.20(0.44)$ & $-0.26(-0.83)$ & $-0.46(-0.39)$ & $24.22(24.32)$ \\
\hline & & TRP & $-0.14(0.43)$ & $-0.42(-1.09)$ & $-0.56(-0.66)$ & $25.10(24.96)$ \\
\hline & 5 & $\mathrm{TC}$ & $-0.21(0.43)$ & $-0.19(-0.68)$ & $-0.40(-0.25)$ & $24.00(24.01)$ \\
\hline & & TS & $-0.17(0.44)$ & $-0.27(-0.83)$ & $-0.44(-0.39)$ & $24.21(24.32)$ \\
\hline & & TRP & $-0.10(0.43)$ & $-0.37(-1.09)$ & $-0.49(-0.66)$ & $25.16(25.05)$ \\
\hline & 6 & $\mathrm{TC}$ & $-0.23(0.46)$ & $-0.17(-0.74)$ & $-0.40(-0.28)$ & $24.10(24.15)$ \\
\hline & & TS & $-0.17(0.45)$ & $-0.29(-0.85)$ & $-0.46(-0.40)$ & $24.27(24.35)$ \\
\hline & & TRP & $-0.14(0.43)$ & $-0.41(-1.10)$ & $-0.55(-0.67)$ & $25.14(25.06)$ \\
\hline \multirow[t]{9}{*}{$3^{a, b}(32)^{c}$} & 4 & $\mathrm{TC}$ & $-0.10(0.47)$ & $-0.11(-0.66)$ & $-0.21(-0.19)$ & $32.03(32.00)$ \\
\hline & & TS & $-0.01(0.48)$ & $-0.34(-0.87)$ & $-0.35(-0.38)$ & $32.26(32.32)$ \\
\hline & & TRP & $0.03(0.45)$ & $-0.47(-1.09)$ & $-0.44(-0.64)$ & $33.08(33.03)$ \\
\hline & 5 & $\mathrm{TC}$ & $-0.06(0.47)$ & $-0.18(-0.68)$ & $-0.24(-0.21)$ & $32.00(32.00)$ \\
\hline & & TS & $-0.02(0.46)$ & $-0.34(-0.84)$ & $-0.36(-0.38)$ & $32.26(32.30)$ \\
\hline & & TRP & $0.04(0.45)$ & $-0.44(-1.10)$ & $-0.40(-0.65)$ & $33.16(33.06)$ \\
\hline & 6 & $\mathrm{TC}$ & $-0.17(0.48)$ & $-0.16(-0.76)$ & $-0.33(-0.28)$ & $31.88(32.16)$ \\
\hline & & TS & $-0.04(0.48)$ & $-0.37(-0.86)$ & $-0.41(-0.38)$ & $32.31(32.33)$ \\
\hline & & TRP & $0.03(0.46)$ & $-0.48(-1.11)$ & $-0.46(-0.65)$ & $33.13(33.05)$ \\
\hline
\end{tabular}

${ }^{a}$ Chelpg/AIM atomic charge of carbonyl carbon atom of triplet 1 (-0.33/0.39 au), $2(-0.24 / 0.46 \mathrm{au})$, and $3(-0.05 / 0.48 \mathrm{au}) .{ }^{b} \mathrm{Chelpg} / \mathrm{AIM}$ atomic charge of carbonyl oxygen atom of triplet $1(-0.08 /-0.61 \mathrm{au}), 2(-0.13 /-0.65 \mathrm{au})$, and $3(-0.17 /-0.66 \mathrm{au}) .{ }^{c}$ The total electron population in the respective molecule.

Table 5. Frontier Orbital Energies of the Triplet Carbonyl Compounds and the Hydrogen Donors and Their Respective Electrophicility $(w)$ and Nucleophicility $(N)$ Indexes

\begin{tabular}{lcccc}
\multicolumn{1}{c}{ molecule } & $\begin{array}{c}\text { SOMO }(\mathrm{eV}) / \mathrm{HOMO} \\
(\mathrm{eV})\end{array}$ & $\begin{array}{c}\mathrm{LUMO} \\
(\mathrm{eV})\end{array}$ & $w(\mathrm{eV})$ & $\begin{array}{c}\mathrm{N} \\
(\mathrm{eV})\end{array}$ \\
$\mathrm{T}_{1}$ formaldehyde & $-1.78^{a}$ & 1.23 & 0.013 & \\
$\mathrm{~T}_{1}$ acetaldehyde & $-1.49^{b}$ & 1.18 & 0.005 & \\
$\mathrm{~T}_{1}$ acetone & $-1.29^{c}$ & 1.14 & 0.001 & \\
propane & $-8.99^{d}$ & -0.18 & & 0.50 \\
2-propanol & $-7.60^{d}$ & -0.38 & & 1.89 \\
methylamine & $-6.59^{d}$ & -0.31 & & 2.90 \\
${ }^{a}$ SOMO-1 $=-4.419$ & $\mathrm{eV} .{ }^{b} \mathrm{SOMO}-1=$ & $-4.298 \mathrm{eV}$. & ${ }^{c} \mathrm{SOMO}-1=$ \\
$-4.200 \mathrm{eV} .{ }^{d} \mathrm{HOMO}$. & & & & \\
\hline
\end{tabular}

for 6) and not the triplet carbonyl compound (Table 1). For the respective TS, the greater the interatomic distance $\mathrm{R} 3$ $(\mathrm{CO} \cdots \mathrm{H}$, whose averaged values are $1.31 \AA$ for $4,1.40 \AA$ for 5 , and $1.44 \AA$ for 6 ), the more the TS structure resembles a triplet complex. On passing from the TS to TRP, the $\mathrm{C}-\mathrm{O}$ bond lengths increase by a further $2 \%$, and the $\mathrm{C}-\mathrm{H}$ bond of the hydrogen donor is completely cleaved. The formation of the $\mathrm{O}-\mathrm{H}$ bond on passing from the TS to the TRP also reveals a dependence upon the nature of the hydrogen donor. There is, respectively, a $25 \%(4), 31 \pm 1 \%$ (5), and $32 \pm 1 \%$ (6) decrease in $\mathrm{O}-\mathrm{H}$ bond length on passing from the TS to the TRP.

The changes in geometry and reaction energetics on passing from TC to TS to TRP are consistent with the Hammond postulate $^{99}$ in that the TS for hydrogen abstraction from 4 occurs later than that in 5 , which in turn is later than that of 6 . In other words, hydrogen abstraction from 6 occurs in an early TS that more closely resembles the substrates in comparison to the TS for hydrogen abstraction from 4.

Analysis of the bond critical points along the reaction coordinate sheds light on the requirements for hydrogen atom transfer. The BCP 1 represents a polar interaction between the triplet carbonyl compounds and the hydrogen donors that stabilizes the initial geometry of the respective TC (Table 2). However, BCP 3 (a bond critical point associated with an interaction between the $T_{1}$ carbonyl oxygen atom and the hydrogen to be abstracted) for the TC structures is almost zero or is absent (as in the case of reaction with 5 ). For the TCs formed from $\mathbf{1}$ (with $\mathbf{5}$ or $\mathbf{6}$ ) or $\mathbf{2}$ (with 5), BCP 1 is associated with a possible interaction of nonbonding electrons of the hydrogen donor heteroatom $(\mathrm{O}$ or $\mathrm{N})$ with a $\mathrm{C}-\mathrm{H}$ bond of triplet 1 or 2 (Table 2 and Figure 4). An IRC calculation revealed that an in-plane-bending motion, that pivots on the hydrogen atom of BCP 1, brings the electrophilic oxygen atom into proximity with the $\mathrm{C}-\mathrm{H}$ bond that suffers hydrogen 
abstraction, thus leading to the respective TS that possesses a six-membered ring structure (Figure 3). For these systems, on passing from the TC to the TS BCP 1 weakens due to partial charge transfer from the hydrogen donor, and the dominant interactions are given by BCPs 2 and 3. Further, it is interesting to note that, at the TS, the sum of the charge densities for BCP 2 and BCP 3 is almost constant and close to 0.31 e for all of the reactions (Table 2). However, the distance between both reactants $(\mathrm{R} 2+\mathrm{R} 3$ from Table 1$)$ increases in the order $\mathbf{4}<\mathbf{5}<$ 6 for any respective reaction with a $T_{1}$ carbonyl compound. The magnitude of the charge density for $\mathrm{BCP} 2$ is greater than that of BCP 3 in the TS, but on passing from the TS to TRP, BCP 3 has a greater density than BCP 2. The changes reflect that, in the TS, the $\mathrm{C}-\mathrm{H}$ of the hydrogen donor has not been broken, while on forming the TRP, the hydrogen atom has been completely transferred. The results indicate that an average charge density of about $0.3 \mathrm{e}$ between both reactants is associated with the occurrence of the reaction. Further, the required charge density is attained when the respective reacting atoms are at different distances from one another and these geometric parameters are dependent upon the charge donating ability of the hydrogen donor molecule. As expected, methylamine, the best charge donating molecule in the present study, attains the necessary charge density when the reactants are further apart; the average sum of R2 and R3 is $2.640 \AA$ for 6, while the respective sum of R2 and R 3 for 5 is $2.610 \AA$ and 4 is $2.550 \AA$.

Additionally, Figure 1 gives values for the atomic charges of carbon and oxygen of the $\mathrm{C}-\mathrm{O}$ bond for both the $\mathrm{S}_{0}$ and $\mathrm{T}_{1}$ states. Both Chelpg and AIM charges are presented in Table 4 and can be compared. AIM atomic charge ${ }^{81}$ is obtained from the integration of the atomic basin, which is delimited by a zero-flux surface around it, where the dot product between gradient of charge density and normal vectors is zero. Chelpg atomic charge ${ }^{100}$ is an improved method of Chelp atomic charge $^{101}$ derived from the quantum molecular electrostatic potential, which can be obtained from the electric potential. In the case of the $\mathrm{S}_{0}$ state, the carbon atoms of the $\mathrm{C}-\mathrm{O}$ bonds are electron deficient, while the oxygen atoms have an excess of electron density. On excitation of the carbonyl compounds to the respective $T_{1}$ states, there is considerable reorganization of the electron density. The carbon atoms of the $\mathrm{C}-\mathrm{O}$ bonds are reduced by about $0.8 e$ (Chelpg atomic charges), while the oxygen atoms are oxidized by about $0.4 e$. The AIM charges reveal a similar but more accentuated difference between 1, 2, and 3 . In 1 , the carbon atom is reduced by $0.6 e$, and the respective carbon atom of 3 is reduced by $0.5 e$; while the carbon atom of $\mathbf{2}$ has an intermediate value. The oxygen atoms of 1, 2, and 3 are more or less uniformly oxidized by about $0.44 e$ on passing from $S_{0}$ to $\mathrm{T}_{1}$ (AIM charges). By using either Chelpg or AIM charges, it can be clearly seen that, in the $T_{1}$ state, the oxygen atom of the $\mathrm{C}-\mathrm{O}$ bond has considerably less electron density in comparison to the $S_{0}$ state and that the oxygen atom of $\mathbf{1}$ is more electron deficient than 2 or 3 . The calculated changes in electron density on passing from $S_{0}$ to $T_{1}$ are consistent with the electrophilic nature of the $T_{1}$ state for carbonyl compounds.

Analysis of the atomic charges (Chelpg or AIM) and the total electron population at each critical point on the PES reveals differences in the reactions of the hydrogen donors with each triplet carbonyl compound (Table 4). By comparing the total electron population of isolated $T_{1} 1,2$, or 3 , with that of the respective TCs, no change in the total charge of the carbonyl compounds on forming the TC with either $\mathbf{4}$ or $\mathbf{5}$ is observed. However, a small degree of charge transfer occurs when the TC is formed from either $\mathbf{1}$ or $\mathbf{2}$ with $\mathbf{6}$ (Chelpg). The AIM charges indicate that all $\mathrm{T}_{1}$ carbonyl compounds are slightly reduced ( 0.1 to $0.2 e$ ) by charge transfer on formation of the TC with 6 . Notably, $T_{1} 1$ has greater charge transfer than $T_{1} 2$ or 3, consistent with $T_{1} 1$ being more electrophilic (Table 5). With respect to charge transfer in the transition state, there is a considerable increase in the electron density of the carbonyl compounds as a result of charge transfer between reactants. For reactions with $\mathbf{4}$ or $\mathbf{5}$, an average amount of $0.25 \mathrm{e}$ (Chelpg) is transferred to the triplet carbonyl compounds. In the case of $\mathbf{6}$, the degree of charge transfer at the TS more or less doubles in comparison to the respective TC. On the whole, the degree of charge transfer from $\mathbf{6}$ to the respective carbonyl compounds is slightly greater than the respective degree of charge transfer from 4 or 5. This is consistent with the greater nucleophilic character of 6 (Table 5). Further, the total increase in charge $(\mathrm{C} 1+\mathrm{O} 1)$ for 1,2 , and 3 is increasingly negative as the reactions progress along the PES (TC-TS-TRP). Upon forming the TRP, all studied triplet carbonyl reagents have been reduced by one electron (and gained a proton) relative to their respective initial structures.

Changes in the atomic charges of $\mathrm{C} 1$ of the carbonyl group are relatively small along the PES (TC-TS-TRP) but are dependent upon both the nature of the $\mathrm{T}_{1}$ carbonyl compound and the hydrogen donor. The Chelpg charges reveal a more accentuated variation in comparison with the AIM charges, but both reveal similar tendencies. As the $\mathrm{T}_{1}$ carbonyl compound becomes less electrophilic $(1>2>3)$, the atomic charge of $\mathrm{C} 1$ for equivalent critical points on the PES for each hydrogen donor (TC $1-4[5$ or 6$]$, TC $2-4[5$ or 6$]$ or TC $3-4[5$ or 6$]$ and likewise for TS or TRP) becomes less negative (Chelpg) or more positive (AIM). A corresponding analysis of Chelpg atomic charges for $\mathrm{O} 1$ reveals that, for equivalent critical points on the PES for each hydrogen donor, O1 becomes more negative as the $\mathrm{T}_{1}$ carbonyl compound becomes less electrophilic. However, the AIM atomic charges for carbonyl oxygen atom are more uniform along the PES. For each hydrogen donor, the charge on $\mathrm{O} 1$ is essentially the same (for example, TC 1-4 = -0.64, TC 2-4 $=-0.66$, and TC 3-4 $=-0.66$ and likewise for TS or TRP). Notably, the AIM charges for all TRPs reveal $\mathrm{O} 1$ to be more or less uniformly reduced by 1.1e.

Specifically, from consideration of the Chelpg charges, O1 receives the largest part of the charge transfer on passing from $\mathrm{TC}$ to the TS and in the process, the atomic charge of $\mathrm{C} 1$ generally becomes marginally less negative. As the sign and magnitude of the AIM charges for $\mathrm{O} 1$ for each respective critical point of each reaction are similar (but different for each critical point on the PES of an individual reaction), it is more instructive to analyze the percent change of the charge of $\mathrm{O} 1$ with the reaction progress. Table 6 details these percentages.

From Table 6, the percent change in AIM atomic charge for O1 clearly reveals the importance of charge transfer with hydrogen donor 6 on the formation of TC for all $\mathrm{T}_{1}$ carbonyl compounds. The percentage change in charge of $\mathrm{O} 1$ on forming $\mathrm{TC}\left(\mathrm{T}_{1}-\mathrm{TC}\right)$ is at least $50 \%$ of the total charge transferred on formation of the respective TS $\left(\mathrm{T}_{1}-\mathrm{TS}\right)$ relative to the initial charge of $\mathrm{O} 1$ in the $\mathrm{T}_{1}$ carbonyl compounds. Further, to greater or lesser degrees, all $\mathrm{T}_{1}$ carbonyl compounds in the respective TS $\left(\mathrm{T}_{1}-\mathrm{TS}\right)$ are reduced by almost $50 \%$ of the total charge transferred during the reaction $\left(\mathrm{T}_{1}-\mathrm{TRP}\right)$. 
Table 6. Percent Change in O1 Atomic Charge (AIM) for Each Step of the Hydrogen Abstraction Reaction

\begin{tabular}{|c|c|c|c|c|}
\hline \multirow[b]{2}{*}{ reaction step } & \multirow[b]{2}{*}{$\begin{array}{l}\text { carbonyl } \\
\text { compound }\end{array}$} & \multicolumn{3}{|c|}{$\begin{array}{l}\text { percent change }(\%) \text { in } \mathrm{O} 1 \text { atomic } \\
\text { charge (AIM) for each step of the } \\
\left.\text { reaction (and relative to } \mathrm{T}_{1}\right)^{b}\end{array}$} \\
\hline & & $\begin{array}{c}\text { reaction } \\
\mathrm{X}-4\end{array}$ & $\begin{array}{l}\text { reaction } \\
\mathrm{X}-5\end{array}$ & $\begin{array}{c}\text { reaction } \\
\mathrm{X}-6\end{array}$ \\
\hline \multirow[t]{3}{*}{$\mathrm{T}_{1}-\mathrm{TC}^{a}$} & $X=1$ & 5 & 10 & 25 \\
\hline & $X=2$ & 1 & 5 & 14 \\
\hline & $X=3$ & 0 & 3 & 15 \\
\hline \multirow[t]{3}{*}{$\mathrm{TC}-\mathrm{TS}\left(\mathrm{T}_{1}-\mathrm{TS}\right)$} & $X=1$ & $30(36)$ & $24(36)$ & 12 (39) \\
\hline & $X=\mathbf{2}$ & $26(26)$ & $22(26)$ & $15(29)$ \\
\hline & $X=3$ & $32(32)$ & $24(27)$ & $13(30)$ \\
\hline \multirow{3}{*}{$\begin{array}{l}\text { TS-TRP }\left(\mathrm{T}_{1}-\right. \\
\mathrm{TRP})\end{array}$} & $X=1$ & $30(77)$ & $30(77)$ & $28(79)$ \\
\hline & $X=2$ & $31(68)$ & $31(68)$ & 29 (69) \\
\hline & $X=3$ & $25(65)$ & $31(67)$ & $29(68)$ \\
\hline
\end{tabular}

${ }^{a}$ Values of AIM atomic charge for O1 from Figure 1: $1=-0.61 ; 2=$ $-0.65 ; 3=-0.66{ }^{b}$ The positive values indicate an increase in the negative charge on $\mathrm{O} 1$ relative to the initial point of each reaction step. The percent values given in parentheses are relative to the atomic charge on $\mathrm{O} 1$ for the $\mathrm{T}_{1}$ carbonyl compounds.

By taking into consideration the geometric parameters whereby the forming $\mathrm{O} \cdots \mathrm{H}$ bond $(\mathrm{R} 3, \mathrm{CO} \cdots \mathrm{H}$, Table 1$)$ is longer than the breaking $\mathrm{C}-\mathrm{H}$ bond ( $\mathrm{R} 2$, Table 1 ), the results are consistent with early transition states that can be associated with proton coupled electron transfer (PCET) character. $^{38,43,46,102-107}$

Figure 5 provides a graphical representation of the three steps for hydrogen abstraction by triplet 3 with hydrogen donors 4, 5, and 6. Relevant interatomic distances for each mechanistic step of the hydrogen abstraction reaction are given in Table 1 , and Table 3 details the calculated activation free energy $\left(\Delta G_{\mathrm{TS}}\right)$ and the change in reaction free energy $\left(\Delta G_{\text {reac }}\right)$ for each reaction. In the case of hydrogen abstraction from $\mathbf{5}$ or 6, it can be clearly seen from the results in Table 3 and the graphical representation of the PES (Figure 5) that hydrogen abstraction from the $\mathrm{X}-\mathrm{H}$ bond $(\mathrm{X}=\mathrm{O}$ or $\mathrm{N})$ is kinetically and thermodynamically unfavorable. The reactions of the triplets $\mathbf{1}$, $\mathbf{2}$, or $\mathbf{3}$ with the $\mathrm{X}-\mathrm{H}$ bond of $\mathbf{5}$ or $\mathbf{6}$ result in larger values for $\Delta G_{\mathrm{TS}}$ and result in higher energy products due to smaller values of $\Delta G_{\text {reac }}$ in comparison with the respective hydrogen abstraction reaction from the $\mathrm{C}-\mathrm{H}$ bond.

The $\Delta G_{\mathrm{TS}}$ and $\Delta G_{\text {reac }}$ also reveal a dependence on the nature of the hydrogen donor and not the triplet carbonyl compound. With 4 as the hydrogen donor, $\Delta G_{\mathrm{TS}}$ is $8-10 \mathrm{kcal} / \mathrm{mol}$, while the values of $\Delta G_{\mathrm{TS}}$ for 5 and 6 are about $5 \mathrm{kcal} / \mathrm{mol}$ and less than $1 \mathrm{kcal} / \mathrm{mol}$, respectively. Further, $\Delta G_{\text {reac }}$ is increasingly exothermic for the hydrogen donors $4(-4$ to $-5 \mathrm{kcal} / \mathrm{mol}), 5$ $(-8$ to $-10 \mathrm{kcal} / \mathrm{mol})$, and $6(-12$ to $-14 \mathrm{kcal} / \mathrm{mol})$. These results indicate that the electronic nature of the triplet carbonyl compounds 1, 2, and 3 is similar and that they have a similar influence upon hydrogen abstraction from the same hydrogen donor and that the differences in the nature of the hydrogen donors strongly influences the rate of the hydrogen abstraction reaction.

Additionally, Table 3 gives values for $\Delta G_{\mathrm{TS}}$ and $\Delta G_{\text {reac }}$ for the reaction of $\mathbf{2}$ with $\mathbf{4}$ or $\mathbf{5}$ with acetonitrile as solvent as determined by the use of IEFPCM calculations. Unfortunately, the corresponding calculations with $\mathbf{6}$ did not result in the localization of a TS for $\mathrm{C}-\mathrm{H}$ bond cleavage. Further, the IEFPCM optimization calculation for the triplet complex yielded a radical pair as a maximum on the PES. Both results converge to the possible existence of a barrierless TS for triplet 2 reacting with $\mathbf{6}$. As all the studied triplet carbonyl compounds reacting with 6 have very similar activation energies, it is expected that all of them will have a barrierless TS in the first step of the hydrogen abstraction reaction. In accord with this, all attempts to locate a TS for the reactions of $\mathbf{1}$ and $\mathbf{3}$ with $\mathbf{6}$ using the acetonitrile dielectric constant for the solvation cavity were unsuccessful.

For the reaction of $\mathbf{2}$ with $\mathbf{4}$ or $\mathbf{5}$ (and presumably the reactions of 1 and 3 with either 4 or 5 ), the values for $\Delta G_{\mathrm{TS}}$ and $\Delta G_{\text {reac }}$ using the continuum model with acetonitrile as solvent are very similar to the gas phase values. The results are consistent with a pronounced radical-like character for these reations.

\section{CONCLUSIONS}

The triplet aliphatic carbonyl compounds in this study reveal that hydrogen abstraction is thermodynamically and kinetically favored from methylamine with respect to 2-propanol, and 2propanol is favored with respect to propane. Further, methine hydrogen abstraction from 2-propanol and the equivalent hydrogen abstraction from methylamine are thermodynamically and kinetically favored with respect to hydrogen abstraction from either the $\mathrm{OH}$ or the $\mathrm{NH}$ functional groups.

For the hydrogen abstraction reactions using 6 as the hydrogen donor, charge transfer takes place before the TS. Additionally, the TS structures involving the triplet carbonyl compounds and $\mathbf{6}$ are earlier than the respective TS structures for the hydrogen donors 4 and 5. The reactions involving 6 as the hydrogen donor have smaller activation energies, and the TS structures more closely resemble the substrate structures. When solvent effects were taken into consideration by use of the continuum solvation model, with acetonitrile as solvent, the hydrogen abstraction from 6 by triplets 1,2 , or 3 were found to have a barrierless TS.

Charge transfer was also found to occur in the reactions of 4 and $\mathbf{5}$ as hydrogen donors, but only in the respective TS structures. Notably, the extent of charge transfer for these hydrogen donors was essentially the same in the gas phase.

For the reactions of 4 or 5 with the triplets 1 , 2, or 3, the charge transfer cannot be directly correlated with the activation energy barrier or the reaction free energy. There is little influence of the electronic nature of the triplet carbonyl compounds on the rate of the hydrogen abstraction from 4 (or 5), as the reactions of the triplets with 4 (or with 5) have very similar activation barriers. However, the average difference for the activation energy for hydrogen abstraction from 4 and 5 is 4 $\mathrm{kcal} \cdot \mathrm{mol}^{-1}$.

The $\mathrm{T}_{1}$ carbonyl compounds are reduced by 0.2 to $0.3 e$ in the TS. This effectively corresponds to about $50 \%$ of the total change in electron density of the oxygen atom of the carbonyl compounds in the course of the reaction. However, the respective $\mathrm{C}-\mathrm{H}$ bonds are not significantly broken, thus indicating that the hydrogen abstraction reactions have early transition states (to a greater, as in reaction with 6 , or lesser extent as in reaction with 4 ).

\section{AUTHOR INFORMATION}

\section{Corresponding Author}

*E-mail: caiofirme@quimica.ufrn.br (C.L.F.); rcorrea@iq.ufrj. br (R.J.C.). 


\section{Notes}

The authors declare no competing financial interest.

\section{REFERENCES}

(1) Lai, W. Z.; Li, C. S.; Chen, H.; Shaik, S. Angew. Chem., Int. Ed. 2012, 51, 5556-5578.

(2) Cuquerella, M. C.; Lhiaubet-Vallet, V.; Cadet, J.; Miranda, M. A. Acc. Chem. Res. 2012, 45, 1558-1570.

(3) Schwarz, H. Angew. Chem., Int. Ed. 2011, 50, 10096-10115.

(4) Pratt, D. A.; Tallman, K. A.; Porter, N. A. Acc. Chem. Res. 2011, 44, 458-467.

(5) Mayer, J. M. Acc. Chem. Res. 2011, 44, 36-46.

(6) Borovik, A. S. Chem. Soc. Rev. 2011, 40, 1870-1874.

(7) Baudoin, O. Chem. Soc. Rev. 2011, 40, 4902-4911.

(8) Newhouse, T.; Baran, P. S. Angew. Chem., Int. Ed. 2011, 50, 3362-3374.

(9) Gunay, A.; Theopold, K. H. Chem. Rev. 2010, 110, 1060-1081.

(10) Balcells, D.; Clot, E.; Eisenstein, O. Chem. Rev. 2010, 110, 749823.

(11) Lyngdoh, R. H. D.; Schaefer, H. F. Acc. Chem. Res. 2009, 42, 563-572.

(12) Special issue on $\mathrm{C}-\mathrm{H}$ functionalization edited by Doyle, M. P.; Goldberg, K. I. Acc. Chem. Res. 2012, 45, 777-777.

(13) Special issue on $\mathrm{C}-\mathrm{H}$ functionalization edited by Crabtree, $\mathrm{R}$. H. Chem. Rev. 2010, 110, 575-575.

(14) Turro, N. J.; Ramamurthy, V.; Scaiano, J. C. Principles of Molecular Photochemistry: An Introduction; University Science Books: Sausalito, CA, 2009.

(15) Rubin, M. B. In CRC Handbook of Organic Photochemistry and Photobiology; Horspool, W. M., Song, P.-S., Eds.; CRC Press: Boca Raton, FL, 1995; pp 430-436.

(16) Wagner, P. J.; Park, B.-S. In Organic Photochemistry; Padwa, A., Ed.; Marcel Dekker: New York, 1991; Vol. 11; pp 227-366.

(17) Geraghty, N. W. A.; Lohan, M. T. In CRC Handbook of Organic Photochemistry and Photobiology, 3rd ed.; Griesbeck, A., Oelgemöller, M., Ghetti, F., Eds.; CRC Press: Boca Raton, FL, 2012; pp 445-488.

(18) Wagner, P. J.; Kemppain, A. E.; Schott, H. N. J. Am. Chem. Soc. 1973, 95, 5604-5614.

(19) Wagner, P. J. Acc. Chem. Res. 1971, 4, 168-177.

(20) Walling, C.; Gibian, M. J. J. Am. Chem. Soc. 1965, 87, 33613364.

(21) Turro, N. J. Modern Molecular Photochemistry; University Science Books: Mill Valley, CA, 1991.

(22) Dubois, J. T.; Behrens, H. J. Chem. Phys. 1968, 48, 2647-2650.

(23) Sidman, J. W.; McClure, D. S. J. Am. Chem. Soc. 1955, 77, 6471-6474.

(24) Sidman, J. W.; McClure, D. S. J. Am. Chem. Soc. 1955, 77, 6461-6470.

(25) Turro, N. J.; Wriede, P. A. J. Am. Chem. Soc. 1968, 90, 68636864.

(26) Wagner, P. J.; Hammond, G. S. J. Am. Chem. Soc. 1966, 88, $1245-1251$.

(27) Yang, N. C.; Elliott, S. P. J. Am. Chem. Soc. 1968, 90, 41944195.

(28) Wagner, P. J. J. Am. Chem. Soc. 1967, 89, 2503-2505.

(29) Scaiano, J. C. J. Photochem. 1973, 2, 81-118.

(30) Turro, N. J.; Schore, N.; Hautala, R.; Farringt, G.; Niemczyk, M.; Morton, D.; Dalton, J. C.; Dawes, K. Acc. Chem. Res. 1972, 5, 92101.

(31) Charney, D. R.; Dalton, J. C.; Hautala, R. R.; Snyder, J. J.; Turro, N. J. J. Am. Chem. Soc. 1974, 96, 1407-1410.

(32) Nau, W. M.; Cozens, F. L.; Scaiano, J. C. J. Am. Chem. Soc. 1996, 118, 2275-2282.

(33) Yip, R. W.; Siebrand, W. Chem. Phys. Lett. 1972, 13, 209-212. (34) Pischel, U.; Nau, W. M. J. Am. Chem. Soc. 2001, 123, 97279737.

(35) Tominaga, K.; Yamauchi, S.; Hirota, N. J. Phys. Chem. 1988, 92, $5160-5165$
(36) Das, P. K.; Encinas, M. V.; Scaiano, J. C. J. Am. Chem. Soc. 1981, 103, 4154-4162.

(37) Leigh, W. J.; Lathioor, E. C.; StPierre, M. J. J. Am. Chem. Soc. 1996, 118, 12339-12348.

(38) Lathioor, E. C.; Leigh, W. J. Photochem. Photobiol. 2006, 82, 291-300.

(39) Wagner, P. J.; Truman, R. J.; Scaiano, J. C. J. Am. Chem. Soc. 1985, 107, 7093-7097.

(40) Cohen, S. G.; Baumgart, R. J. Am. Chem. Soc. 1967, 89, 34713475.

(41) Cohen, S. G.; Chao, H. M. J. Am. Chem. Soc. 1968, 90, 165-173.

(42) Cohen, S. G.; Cohen, J. I. J. Am. Chem. Soc. 1967, 89, 164-165.

(43) Cohen, S. G.; Parola, A.; Parsons, G. H. Chem. Rev. 1973, 73, 141-161.

(44) Cohen, S. G.; Stein, N. M. J. Am. Chem. Soc. 1971, 93, 65426551.

(45) Griller, D.; Howard, J. A.; Marriott, P. R.; Scaiano, J. C. J. Am. Chem. Soc. 1981, 103, 619-623.

(46) Simon, J. D.; Peters, K. S. J. Am. Chem. Soc. 1982, 104, 65426547.

(47) Hammes-Schiffer, S. In Hydrogen-Transfer Reactions; Hynes, J. T., Klinman, J. P., Limbach, H.-H., Schowen, R. L., Eds.; Wiley-VCH Verlag GmbH \& Co. KGaA: Weinheim, Germany, 2007; pp 479-502.

(48) Hodgkiss, J. M.; Rosenthal, J.; Nocera, D. G. In HydrogenTransfer Reactions; Hynes, J. T., Klinman, J. P., Limbach, H.-H., Schowen, R. L., Eds.; Wiley-VCH Verlag GmbH \& Co. KGaA: Weinheim, Germany, 2007; pp 503-562.

(49) Chutjian, A. J. Chem. Phys. 1974, 61, 4279-4284.

(50) Foresman, J. B.; Headgordon, M.; Pople, J. A.; Frisch, M. J. J. Phys. Chem. 1992, 96, 135-149.

(51) Hadad, C. M.; Foresman, J. B.; Wiberg, K. B. J. Phys. Chem. 1993, 97, 4293-4312.

(52) Harding, L. B.; Goddard, W. A. J. Am. Chem. Soc. 1975, 97, 6293-6299.

(53) Moule, D. C.; Walsh, A. D. Chem. Rev. 1975, 75, 67-84.

(54) Weiss, M. J.; Kuyatt, C. E.; Mielczar, S. J. Chem. Phys. 1971, 54, $4147-4150$

(55) Wiberg, K. B.; Stratmann, R. E.; Frisch, M. J. Chem. Phys. Lett. 1998, 297, 60-64.

(56) Harding, L. B.; Goddard, W. A. J. Am. Chem. Soc. 1977, 99, 677-683.

(57) Angeli, C.; Borini, S.; Ferrighi, L.; Cimiraglia, R. J. Mol. Struct. 2005, 718, 55-69.

(58) Du, Y.; Ma, C. S.; Kwok, W. M.; Xue, J. D.; Phillips, D. L. J. Org. Chem. 2007, 72, 7148-7156.

(59) Frank, I.; Hutter, J.; Marx, D.; Parrinello, M. J. Chem. Phys. 1998, 108, 4060-4069.

(60) Jensen, P.; Bunker, P. R. J. Mol. Spectrosc. 1982, 94, 114-125.

(61) Ogurtsov, I. Y.; Munteanu, G.; Bantush, L.; Bersuker, I. B. J. Mol. Struct. 2001, 541, 141-148.

(62) Severance, D.; Pandey, B.; Morrison, H. J. Am. Chem. Soc. 1987, 109, 3231-3233.

(63) Pischel, U.; Nau, W. M. Photochem. Photobiol. Sci. 2002, 1, 141147.

(64) Gunnarsson, O.; Jonson, M.; Lundqvist, B. I. Phys. Lett. A 1976, $59,177-179$.

(65) Gunnarsson, O.; Jonson, M.; Lundqvist, B. I. Phys. Rev. B 1979, $20,3136-3164$.

(66) Gunnarsson, O.; Lundqvist, B. I. Phys. Rev. B 1976, 13, 42744298.

(67) Koch, W.; Holthausen, M. C. A Chemist's Guide To Density Functional Theory, 2nd ed.; Wiley-VCH: Weinheim, Germany, 2001.

(68) de Lucas, N. C.; Correa, R. J.; Albuquerque, A. C. C.; Firme, C. L.; Garden, S. J.; Bertoti, A. R.; Netto-Ferreira, J. C. J. Phys. Chem. A 2007, 111, 1117-1122.

(69) de Lucas, N. C.; Elias, M. M.; Firme, C. L.; Correa, R. J.; Garden, S. J.; Netto-Ferreira, J. C.; Nicodem, D. E. J. Photochem. Photobiol., A 2009, 201, 1-7. 
(70) de Lucas, N. C.; Fraga, H. S.; Cardoso, C. P.; Correa, R. J.; Garden, S. J.; Netto-Ferreira, J. C. Phys. Chem. Chem. Phys. 2010, 12, 10746-10753.

(71) Li, X.; Frisch, M. J. J. Chem. Theory Comput. 2006, 2, 835-839.

(72) Pulay, P.; Fogarasi, G. J. Chem. Phys. 1992, 96, 2856-2860.

(73) Becke, A. D. J. Chem. Phys. 1993, 98, 5648-5652.

(74) Dunning, J. T. H. J. Chem. Phys. 1989, 90, 1007-1023.

(75) Lee, C.; Yang, W.; Parr, R. G. Phys. Rev. B 1988, 37, 785-789.

(76) Frisch, M. J.; Trucks, G. W.; Schlegel, H. B.; Scuseria, G. E.; Robb, M. A.; Cheeseman, J. R.; Zakrzewski, V. G.; Montgomery, J. A. J.; Vreven, T.; Kudin, K. N.; et al. Gaussian 09, revision A1; Gaussian. Inc.: Wallingford, CT, 2009.

(77) Cances, E.; Mennucci, B.; Tomasi, J. J. Chem. Phys. 1997, 107, 3032-3041.

(78) Mennucci, B.; Tomasi, J. J. Chem. Phys. 1997, 106, 5151-5158.

(79) Breneman, C. M.; Wiberg, K. B. J. Comput. Chem. 1990, 11, 361-373.

(80) Roothaan, C. C. J. Rev. Mod. Phys. 1960, 32, 179-185.

(81) Bader, R. F. W. Atoms in Molecules: A Quantum Theory, 1st ed.; Oxford Publisher: Oxford, U.K., 1994.

(82) Biegler-König, F.; Schönbohm, J. AIM2000, version 2.0, 2002.

(83) Keith, T. A.; AIMALL, version 12.09.23; TK Gristmill Software: Overland Park, 2012.

(84) Perez-Prieto, J.; Stiriba, S. E.; Bosea, F.; Lahoz, A.; Domingo, L. R.; Monti, S.; Miranda, M. A. J. Org. Chem. 2004, 69, 8618-8625.

(85) Perez-Prieto, J.; Bosca, F.; Galian, R. E.; Lahoz, A.; Domingo, L. R; Miranda, M. A. J. Org. Chem. 2003, 68, 5104-5113.

(86) Pan, Y.; Fu, Y.; Liu, S. X.; Yu, H. Z.; Gao, Y. H.; Guo, Q. X.; Yu,

S. Q. J. Phys. Chem. A 2006, 110, 7316-7322.

(87) Tominaga, K.; Yamauchi, S.; Hirota, N. J. Chem. Phys. 1990, 92, $5175-5185$.

(88) Levstein, P. R.; Vanwilligen, H. J. Chem. Phys. 1991, 95, 900908.

(89) Bader, R. F. W. J. Phys. Chem. A 1998, 102, 7314-7323.

(90) Noble, M.; Lee, E. K. C. J. Chem. Phys. 1984, 81, 1632-1642.

(91) Borkman, R. F.; Kearns, D. R. J. Chem. Phys. 1966, 44, 945-949.

(92) Angeli, C.; Borini, S.; Ferrighi, L.; Cimiraglia, R. J. Chem. Phys.

2005, 122, 114304-114310.

(93) Domingo, L. R.; Aurell, M. J.; Perez, P.; Saez, J. A. RSC Adv. 2012, 2, 1334-1342.

(94) Parr, R. G.; Von Szentpaly, L.; Liu, S. B. J. Am. Chem. Soc. 1999, 121, 1922-1924.

(95) Domingo, L. R.; Chamorro, E.; Perez, P. J. Org. Chem. 2008, 73, 4615-4624.

(96) Bokarev, S. L.; Dolgov, E. K.; Godunov, I. A. Russ. Chem. Bull. 2005, 54, 2714-2725.

(97) Munozcaro, C.; Nino, A.; Moule, D. C. J. Mol. Struct. 1994, 121, 9-17.

(98) Liu, D.; Fang, W. H.; Fu, X. Y. Chem. Phys. Lett. 2000, 325, 8692.

(99) Hammond, G. S. J. Am. Chem. Soc. 1955, 77, 334-338

(100) Breneman, C. M.; Wiberg, K. B. J. Comput. Chem. 1990, 11, 361-373.

(101) Chirlian, L. E.; Francl, M. M. J. Comput. Chem. 1987, 8, 894905.

(102) Inbar, S.; Linschitz, H.; Cohen, S. G. J. Am. Chem. Soc. 1981, 103, 1048-1054.

(103) Miyasaka, H.; Morita, K.; Kamada, K.; Mataga, N. Chem. Phys. Lett. 1991, 178, 504-510.

(104) Mayer, J. M.; Hrovat, D. A.; Thomas, J. L.; Borden, W. T. J. Am. Chem. Soc. 2002, 124, 11142-11147.

(105) Mayer, J. M. Annu. Rev. Phys. Chem. 2004, 55, 363-390.

(106) Isborn, C.; Hrovat, D. A.; Borden, W. T.; Mayer, J. M.; Carpenter, B. K. J. Am. Chem. Soc. 2005, 127, 5794-5795.

(107) Tishchenko, O.; Truhlar, D. G.; Ceulemans, A.; Nguyen, M. T. J. Am. Chem. Soc. 2008, 130, 7000-7010. 